\title{
Continuous Glucose Monitoring in 2017
}

\author{
Tadej Battelino ${ }^{1,2}$ and Bruce W. Bode ${ }^{3,4}$
}

\section{Introduction}

G OOD CLINICAL PRACTICE MAKES IT possible to develop clinical guidelines andwhen endorsed by respective professional associations-mandates following them in routine clinical practice. Continuous glucose monitoring (CGM) finally reached the stage at which most of the respected professional associations in the field of diabetes and endocrinology decided to develop clinical guidelines for routine use of CGM. The Endocrine Society along with the American Association for Clinical Chemistry, the American Association of Diabetes Educators, and the European Society of Endocrinology published a Clinical Practice Guideline on diabetes technology, carefully evaluating the existing published evidence for adult population with diabetes and concluded that continuous subcutaneous insulin infusion (CSII) and CGM have an important role in the treatment of diabetes (1). The guideline recommends at the highest level of published evidence the use of CGM devices for adult patients with uncontrolled and well-controlled type 1 diabetes mellitus (T1D) who are willing and able to use these devices on a nearly daily basis. This is remarkable and immensely important for our everyday clinical practice. Additionally, with a grade 2 level of evidence, the guideline also recommends short-term, intermittent CGM use in adult patients with type 2 diabetes mellitus (T2D) (not on prandial insulin) who have A1c $>7 \%$ and are willing and able to use the device (1). Several recently published reviews, some with meta-analysis of individual data, support this recommendation with demonstrating a reduction in glycated hemoglobin (HbAlc) (2), a clinical benefit in outcome trials in T1D and T2D treated with multiple daily injections (MDI) (3), a reduction in hypoglycemia (4), a clinical benefit in T2D (5), a clinical benefit in a pediatric population with T1D (6), and a clinical benefit in professional use (7). Additionally, CGM is recommended as a standard tool in different daily situations (e.g., exercise and sports) and in clinical trials in T1D and T2D $(8,9)$. This article reviews strong clinical evidence supporting nonadjunctive use of CGM and again discusses evidence demonstrating the importance of time in range and glucose variability (GV).

\section{Key Articles Reviewed for the Article}

Novel glucose-sensing technology and hypoglycaemia in type 1 diabetes: a multicentre, non-masked, randomised controlled trial

Bolinder J, Antuna R, Geelhoed-Duijvestijn P, Kröger J, Raimund Weitgasser $R$

Lancet 2016; 388: 2254-2263

Effect of continuous glucose monitoring on glycemic control in adults with type 1 diabetes using insulin injections: the DIAMOND randomized clinical trial

Beck RW, Riddlesworth T, Ruedy K, Ahmann A, Bergenstal R, Halle S, Kollman C, Kruger $D$, McGill JB, Polonsky W, Toschi E, Wolpert H, Price D; for the DIAMOND Study Group JAMA 2017; 317: 371-378

\footnotetext{
${ }^{1}$ UMC-University Children's Hospital Ljubljana, and ${ }^{2}$ Faculty of Medicine, University of Ljubljana, Ljubljana, Slovenia
}

${ }^{3}$ Atlanta Diabetes Associates, Atlanta, Georgia, and ${ }^{4}$ Emory University School of Medicine, Atlanta, Georgia. 
Continuous glucose monitoring vs conventional therapy for glycemic control in adults with type 1 diabetes treated with multiple daily insulin injections: the GOLD randomized clinical trial

Lind M, Polonsky W, Hirsch IB, Heise T, Bolinder J, Dahlqvist S, Schwarz E, Ólafsdóttir AF, Frid A, Wedel H, Ahlén E, Nyström T, Hellman J

JAMA 2017: 317: 379-387

Continuous glucose monitoring for patients with type 1 diabetes and impaired awareness of hypoglycemia (IN CONTROL): a randomized, open-label, crossover trial

van Beers CAJ, DeVries JH, Kleijer SJ, Smits MM, Geelhoed-Duijvestijn PH,

Kramer MHH, Diamant M, Snoek FJ, Serné EH

Lancet Diabetes Endocrinol 2016; 4: 893-902

REPLACE-BG: a randomized trial comparing continuous glucose monitoring with and without routine blood glucose monitoring in well-controlled adults with type 1 diabetes

Aleppo G, Ruedy KJ, Riddlesworth TD, Kruger DF, Peters AL, Hirsch I, Bergenstal RM, Toschi E, Ahmann AJ, Shah VN, Rickels MR, Bode BW, Philis-Tsimikas A, Pop-Busui R, Rodriguez H, Eyth E, Bhargava A, Kollman C, Beck RW; for the REPLACE-BG Study Group

Diabetes Care 2017; 40: 538-545

Hypoglycemic event frequency and the effect of continuous glucose monitoring in adults with type 1 diabetes using multiple daily insulin injections

Riddlesworth T, Price D, Cohen N, Beck RW

Diabetes Ther 2017; 8: 947-951

Continuous glucose monitoring in older adults with type 1 and type 2 diabetes using multiple daily injections of insulin: results from the DIAMOND trial

Ruedy KJ, Parkin CG, Riddlesworth TD, Graham C; for the DIAMOND Study Group

J Diabetes Sci Technol 2017; 11: 1138-1146

Effect of initiating use of an insulin pump in adults with type 1 diabetes using multiple daily insulin injections and continuous glucose monitoring (DIAMOND): a multicentre, randomised controlled trial

Beck RW, Riddlesworth TD, Ruedy KJ, Kollman C, Ahmann AJ, Bergenstal RM, Bhargava A, Bode BW, Haller S, Kruger DF, McGill JB, Polonsky W, Price D, Toschi E; for the DIAMOND Study Group

Lancet Diabetes Endocrinol 2017; 5: 700-708

"Let the algorithm do the work": reduction of hypoglycemia using sensor-augmented pump therapy with predictive insulin suspension (SmartGuard) in pediatric type 1 diabetes patients

Biester T, Kordonouri O, Holder M, Remus K, Kieninger-Baum D, Wadien T, Danne $T$

Diabetes Technol Ther 2017; 19: 173-182

Prevention of hypoglycemia with predictive low glucose insulin suspension in children with type 1 diabetes: a randomized controlled trial

Battelino T, Nimri R, Dovc $K$, Phillip M, Bratina $N$

Diabetes Care 2017; 40: 764-770

Schooling diabetes: use of continuous glucose monitoring and remote monitors in the home and school settings

Erie C, Van Name MA, Weyman K, Weinzimer SA, Finnegan J, Sikes $K$,

Tamborlane $W V$, Sherr JL

Pediatr Diabetes 2017 Mar 17. [Epub ahead of print] DOI 10.1111/pedi.12518 


\author{
Striving for control: lessons learned from a successful international Type 1 \\ Diabetes Youth Challenge \\ Kordonouri O, Vazeou A, Scharf M, Würsig M, Battelino T; for the SWEET Group \\ Acta Diabetol 2017; 54: 403-409
}

Retinal neurodegeneration in patients with type 1 diabetes mellitus: the role of glycemic variability

Picconi F, Parravano M, Ylli D, Pasqualetti P, Coluzzi S, Giordani I, Malandrucco I, Lauro D, Scarinci F, Giorno P, Varano M, Frontoni $S$

Acta Diabetol 2017; 54: 489-497

Relationship between glucose fluctuations and ST-segment resolution in patients with ST-elevation acute myocardial infarction

Tsuchida K, Nakamura N, Soda S, Sakai R, Nishida K, Hiroki J, Kashiwa A, Fujihara Y, Kimura S, Hosaka Y, TakahashiI K, Oda $H$

Int Heart J 2017; 58: 328-334

Post stroke dysglycemia and acute infarct volume growth: a study using continuous glucose monitoring

Shimoyama T, Kimura K, Uemura J, Saji N, Shibazaki $K$

Eur Neurol 2016; 76: 167-174

Impact of glycemic variability on chromatin remodeling, oxidative stress and endothelial dysfunction in type 2 diabetic patients with target $\mathrm{HbA}_{1 \mathrm{c}}$ levels

Costantino S, Paneni F, Battista R, Castello L, Capretti $G$, Chiandotto $S$, Tanese L, Russo G, Pitocco D, Lanza GA, Volpe M, Lüscher TF, Cosentino $F$

Diabetes 2017; 66: 2472-2482

\section{Novel glucose-sensing technology and hypoglycaemia in type 1 diabetes: a multicentre, non-masked, randomised controlled trial}

Bolinder $J^{1}$, Antuna $R^{2}$, Geelhoed-Duijvestijn $P^{3}$, Kröger $J^{4}$, Raimund Weitgasser $R^{5,6}$

${ }^{I}$ Department of Medicine, Karolinska University Hospital Huddinge, Karolinska Institute, Stockholm, Sweden; ${ }^{2}$ Clinidiabet, Corrida, Gijon, Spain; ${ }^{3}$ Department of Internal Medicine, Medical Center Haaglanden, The Hague, Netherlands; ${ }^{4}$ Centre for Diabetology Hamburg Bergedorf, Hamburg, Germany; ${ }^{5}$ Department of Internal Medicine, Wehrle-Diakonissen Hospital Salzburg, Austria; ${ }^{6}$ Paracelsus Medical University, Salzburg, Austria

Lancet 2016; 388: 2254-2263

\section{Aims}

Hypoglycemia remains a barrier in maintaining good glycemic control. Several technologies using continuous glucose monitoring have demonstrated improved glycemic control with concomitant reduction in the duration or rate of hypoglycemia. There has been no data on flash glucose monitoring (FGM) from randomized controlled trials. This study aimed to assess the efficacy of flash glucose monitoring technology in comparison with self-monitoring of blood glucose (SMBG), focusing on prevention of hypoglycemia in adults with well-controlled type 1 diabetes.

\section{Methods}

The sensor of the (FGM) system (Freestyle Libre; Abbott Diabetes Care, Witney, Oxon, UK) is precalibrated at the factory and is ready for a 14-day use without any additional calibration by the user. The reader acquires data when in proximity of the sensor/transmitter and displays current sensor glucose concentration, a glucose trend arrow, and glucose history for 8 hours; all data is stored for 90 days. From the reader, data can be uploaded to generate summary glucose reports by the patient or health-care professional (HCP). Adult (age $>18$ years) participants from 23 European diabetes centers ( 3 in Sweden, 6 in Austria, 5 in Germany, 3 in Spain, and 6 in the Netherlands) were invited if they had type 1 diabetes for $>5$ years, were on a stable insulin regimen for $>3$ months, had a screening $\mathrm{HbA} 1 \mathrm{c} \leq 7.5 \%(58 \mathrm{mmol} /$ $\mathrm{mol}$ ), and reported performing SMBG $\geq 3$ times a day for 2 months. Participants with hypoglycemia unawareness, diabetic ketoacidosis, or myocardial infarction in the preceding 6 months, who used CGM within the preceding 4 months or were using a sensor-augmented pump (SAP), were pregnant/ planning pregnancy, or were receiving oral steroid therapy were not invited. After a 14-day run-in with a blinded FGM, participants were randomized 1:1 to either FGM or SMBG for 6 months. FGM was recorded in both groups for 14 days at 3 and 6 months. The primary outcome was time in hypoglycemia $<3.9 \mathrm{mmol} / \mathrm{L}(<70 \mathrm{mg} / \mathrm{dL})$ during the 6 months with FGM. Several secondary glycemic outcomes based on the same FGM period along with QOL questionnaires were planned. 


\section{Results}

Results were calculated from 239 participants out of 241 randomized. Time in hypoglycemia $<3.9 \mathrm{mmol} / \mathrm{L}$ changed from $3.38 \mathrm{~h} /$ day to $2.03 \mathrm{~h} /$ day in the intervention group (baseline adjusted mean change -1.39 ), and from $3.44 \mathrm{~h} /$ day to $3.27 \mathrm{~h} /$ day in the control group (baseline adjusted mean change -0.14$)$, with the adjusted between group difference of $-1.24($ SE $0.239 \mathrm{~h} /$ day $)(P<0.0001)$, representing a $38 \%$ reduction in time in hypoglycemia in the FGM group compared with the SMBG group. This analysis was also significant for other hypoglycemia thresholds $(<3.1 \mathrm{mmol} / \mathrm{L}$, $<2.5 \mathrm{mmol} / \mathrm{L}$, and $<2.2 \mathrm{mmol} / \mathrm{L}$ ) in favor of the intervention group, along with the number of hypoglycemic events at each hypoglycemic threshold. At 6 months, 77 (65\%) of the FGM group reduced their time in hypoglycemia $(<3.9 \mathrm{mmol} / \mathrm{L})$ by at least $30 \%(P<0.0001)$ compared with $39(33 \%)$ of the control group. Time in range of sensor glucose 3.9$10.0 \mathrm{mmol} / \mathrm{L}$ was significantly longer in the FGM group as compared with the self-monitoring of blood glucose (SMBG) group at 6 months, with time spent in hyperglycemia ( $>13.3 \mathrm{mmol} / \mathrm{L})$ reduced more in the FGM group. All analyzed glycemic variability measures (glucose standard deviation, mean amplitude of glycemic excursions [MAGE], low blood glucose index [LBGI], and blood glucose risk index) significantly favored the FGM group as compared with SMBG. The mean number of SMBG tests performed per day by the FGM group immediately diminished from 5.5 (SD 2.0) to $0.5(0.7)$ tests per day during the intervention period, with a mean number of FGM scans per day of 15.1 (SD 6.9). The total treatment satisfaction $(6.1[0.84] ; \mathrm{P}<0.0001)$ and perceived frequency of hyperglycemia $(-1.0[0.22] ; \mathrm{P}<0.0001)$ were significantly improved in the FGM group compared with the SMBG group. No differences in diabetes distress, hypoglycemia fear behavior, or worry scores were observed. Five serious adverse events in each group were reported by 9 participants, none related to the device.

\section{Conclusions}

The use of FGM resulted in a significant reduction in time and incidence of hypoglycemia, without deterioration in $\mathrm{HbA} 1 \mathrm{c}$ levels, in well-controlled individuals with type 1 diabetes. Additionally, time in hyperglycemia was also significantly reduced, which significantly improved patients' satisfaction score.

\section{Comments}

This large randomized controlled trial brings important solidification of existing knowledge: more information on glucose values decreases hypoglycemia without deterioration in overall metabolic control in well-controlled individuals with T1D. Moreover, in this particular study, time in hyperglycemia was also significantly decreased, along with all measures of glucose variability, which may finally be the most clinically relevant outcome. Not quite in line with the protocol, the FGM device was largely used as a replacement for SMBG in the intervention group, with an average of $<1 \mathrm{SMBG}$ per day while using FGM. This confirms results from other trials with CGM devices in which the use of SMBG is spontaneously reduced by the users of CGM (10). Some caution may be needed when a complete replacement of SMBG by FGM is exercised (11). Finally, some aspects of quality of life were improved with the use of FGM. Interestingly, satisfaction with reducing hyperglycemia reached statistical significance while measures related to hypoglycemia did not. Well-controlled individuals with T1D may be more concerned with hyperglycemia than hypoglycemia and rightfully so.

\section{Effect of continuous glucose monitoring on glycemic control in adults with type 1 diabetes using insulin injections: the DIAMOND randomized clinical trial}

Beck $R W^{l}$, Riddlesworth $T^{l}$, Ruedy $K^{l}$, Ahmann $A^{2}$, Bergenstal $R^{3}$, Halle $S^{4}$, Kollman $C^{1}$, Kruger $D^{5}$, McGill $\mathrm{JB}^{6}$, Polonsky $W^{7}$, Toschi $E^{8}$, Wolpert $H^{8}$, Price $D^{9}$; for the DIAMOND Study Group

${ }^{1}$ Jaeb Center for Health Research, Tampa, FL; ${ }^{2}$ Oregon Health \& Science University, Portland, OR; ${ }^{3}$ Park Nicollet Institute, International Diabetes Center, St Louis Park, MN; ${ }^{4}$ Diabetes Glandular Disease Clinic, San Antonio, TX; ${ }^{5}$ Division of Endocrinology, Henry Ford Medical Center, Detroit, MI; ${ }^{6}$ Washington University in St. Louis, St. Louis, MO; ${ }^{7}$ Behavioral Diabetes Institute, San Diego, CA; ${ }^{8}$ Joslin Diabetes Center, Boston, MA; ${ }^{9}$ Dexcom Inc., San Diego, CA

JAMA 2017; 317: 371-378

\section{Aims}

To determine the efficacy and safety of continuous glucose monitoring (CGM) in adults with type 1 diabetes treated with multiple daily insulin injections (MDI).

\section{Methods}

The trial included 158 adults with type 1 diabetes on MDI with HbA1c between $7.5 \%$ and $9.9 \%$. Participants were randomly assigned $2: 1$ to CGM $(n=105)$ or usual care with SMBG $(n=53)$. Primary endpoint was the difference in the change in HbA1c from baseline to 24 weeks. Eighteen secondary or other exploratory endpoints were also measured including duration of hypoglycemia less than $70 \mathrm{mg} / \mathrm{dL}$ measured with masked CGM for 7 days at 12 and 24 weeks.

\section{Results}

A total of 155 (98\%) participants completed the study. In the CGM group, 93\% used CGM $\geq 6$ days/week in month 6 . Mean $\mathrm{HbA} 1 \mathrm{c}$ reduction from baseline was $1.1 \%$ at 12 weeks and $1.0 \%$ at 24 weeks in the CGM group and $0.5 \%$ and $0.4 \%$ respectively in the SMBG group $(P<0.001)$. The adjusted treatment-group difference in mean change in $\mathrm{HbA} 1 \mathrm{c}$ from baseline was $0.6 \%$ [95\% confidence interval $(\mathrm{CI})-0.8 \%,-0.3 \%](P<0.001)$. Median duration of hypoglycemia $(<70 \mathrm{mg} / \mathrm{dL})$ was $43 \mathrm{~min} /$ day (IQR 27-69) in the CGM group vs. $80 \mathrm{~min} /$ day (IQR 36$111)$ in the SMBG group $(P=0.002)$. Two participants in each group had severe hypoglycemia events.

\section{Conclusion}

In adults with type 1 diabetes who are using MDI, the use of CGM compared with usual care with SMBG resulted in 
a significant decrease in $\mathrm{HbA1c}$ with less duration of hypoglycemia during the 24-week study.

\section{Comments}

The DIAMOND randomized clinical trial has demonstrated that the use of CGM in patients with type 1 diabetes on MDI show a significant decrease in HbA1c with less duration of hypoglycemia defined as $<70 \mathrm{mg} / \mathrm{dL}$. These results from this randomized study are similar to the results of patients with type 1 diabetes on insulin pump therapy who are not at goal; both improved HbA1c with less time spent in hypoglycemia. Further research is needed to assess the benefits of CGM in type 1 patients on MDI who have $\mathrm{HbA} 1 \mathrm{c}<7.5 \%$ as well $\mathrm{HbA} 1 \mathrm{c}>9.9 \%$ as well as in subjects who are $<18$ years of age.

\section{Continuous glucose monitoring vs conventional therapy for glycemic control in adults with type 1 diabetes treated with multiple daily insulin injections: the GOLD randomized clinical trial}

Lind $M^{1,2}$, Polonsky $W^{3}$, Hirsch $I^{4}{ }^{4}$, Heise $T^{5}$, Bolinder $J^{6}$, Dahlqvist $S^{2}$, Schwarz $E^{7}$, Ólafsdóttir $A F^{2}$, Frid $A^{8,9}$, Wedel $H^{10}$, Ahlén $E^{1,2}$, Nyström $T^{l l}$, Hellman $J^{12}$

${ }^{1}$ Department of Molecular and Clinical Medicine, University of Gothenburg, Gothenburg, Sweden; ${ }^{2}$ Department of Medicine, NU Hospital Group, Uddevalla, Sweden; ${ }^{3}$ University of California, San Diego, La Jolla, CA; ${ }^{4}$ University of Washington, School of Medicine, Seattle, WA; ${ }^{5}$ Profil, Neuss, Germany; ${ }^{6}$ Department of Medicine, Karolinska University Hospital Huddinge, Karolinska Institute, Stockholm, Sweden; ${ }^{7}$ Department of Internal Medicine, Faculty of Medicine and Health, Örebro University, Örebro, Sweden; ${ }^{8}$ Division of Endocrinology, Department of Clinical Sciences, Skåne University Hospital, Malmö, Sweden; ${ }^{9}$ Lund University, Lund, Sweden; ${ }^{10}$ Health Metrics Sahlgrenska Academy at University of Gothenburg, Sweden; ${ }^{1}$ Department of Clinical Science and Education, Södersjukhuset, Karolinska Institute, Stockholm, Sweden; ${ }^{12}$ Department of Medical Sciences, Clinical Diabetes and Metabolism, Uppsala, University, Uppsala, Sweden

JAMA 2017; 317: 379-387

\section{Aims}

The purpose of the study was to evaluate the efficacy of continuous glucose monitoring (CGM) in adults with type 1 diabetes treated with multiple daily injections (MDI).

\section{Methods}

Fifteen diabetes centers in Sweden selected 161 T1D patients treated with MDI and $\mathrm{HbA} 1 \mathrm{c} \geq 7.5 \%$ to be randomized open-label to receive treatment using a CGM system (DexCom G4 Platinum) or conventional treatment with selfmonitoring of blood glucose (SMBG) for 26 weeks, separated by a "washout" period of 17 weeks, followed by the opposite intervention. The primary endpoint was change in HbAlc between weeks 26 and 69 for the two treatments with secondary endpoints being psychosocial and other glycemic parameters and adverse events being severe hypoglycemia.

\section{Results}

In this open-label crossover study, 161 T1D patients on MDI were randomized with a mean $\mathrm{HbA1c}$ of $8.6 \%$; a total of 142 participants completed both treatments. Mean HbA1c was $7.92 \%$ during CGM use and $8.35 \%$ during SMBG only (mean difference $-0.43 \%$ [95\% CI $-0.57 \%$, $-0.29 \%$ ]; $P<0.001)$. Concerning the other secondary endpoints, 6 out of 19 psychosocial and other glycemic measures favored CGM compared with SMBG alone. Five patients in the conventional group had severe hypoglycemia vs. one patient in the CGM group. Seven more patients had severe hypoglycemia during the washout when patients were using SMBG alone.

\section{Conclusion}

Use of CGM in patients with inadequately controlled T1D treated with MDI were shown to have a significant drop in HbA1c by $0.43 \%$ with less risk of severe hypoglycemia compared with the usual care of SMBG.

\section{Comments}

This study is one of several studies that have shown an improvement in $\mathrm{HbA} 1 \mathrm{c}$ by $0.4 \%$ or greater with the use of real-time CGM vs. SMBG alone in T1D patients suboptimally controlled (HbAlc $>7.5 \%$ ) on MDI. In this study, severe hypoglycemia in the CGM group was less. It is now the standard of care that if T1D patients are not reaching their glycemic targets using conventional therapy with SMBG, one should strongly consider placing the patient on a real-time CGM device to better optimize overall glycemic control while both reducing glycemic excursions and preventing severe hypoglycemia.

\section{Continuous glucose monitoring for patients with type 1 diabetes and impaired awareness of hypoglycemia (IN CONTROL): a randomized, open-label, crossover trial}

van Beers $C A J^{1}$, DeVries $J H^{3}$, Kleijer $S J^{1}$, Smits $M M^{1}$, Geelhoed-Duijvestijn $\mathrm{PH}^{5}$, Kramer $\mathrm{MHH}^{1}$, Diamant $\mathrm{M}^{1}$, Snoek $F^{2,4}$, Serné $E H^{1}$

${ }^{1}$ Department of Internal Medicine and ${ }^{2}$ Department of Medical Psychology, VU University Medical Center, Amsterdam, Netherlands; ${ }^{3}$ Department of Endocrinology and ${ }^{4}$ Department of Medical Psychology, Academic Medical Center, University of Amsterdam, Amsterdam, Netherlands; ${ }^{5}$ Department of Internal Medicine, Medical Center Haaglanden, The Hague, the Netherlands

Lancet Diabetes Endocrinol 2016; 4: 893-902

\section{Aims}

A randomized, open-label, crossover trial was conducted to assess whether continuous glucose monitoring (CGM) improves glycemic control and prevents severe hypoglycemia compared with self-monitoring of blood glucose (SMBG) in a high-risk population of type 1 diabetes (T1D) with impaired awareness of hypoglycemia. 


\section{Methods}

T1D patients (age 18-75 years) with impaired awareness of hypoglycemia (Gold score at least 4) were randomized in an open-label crossover trial using real-time CGM at two medical centers in the Netherlands. Patients could be on CSII or MDI and had to be doing at least three glucose measurements per day during the 6-week run-in phase to obtain baseline masked CGM data. Patients were then randomized $1: 1$ to either 16 weeks of CGM followed by 12 weeks of wash-out and then 16 weeks of SMBG or the opposite, 16 weeks of SMBG followed by 12 weeks of wash-out and 16 weeks of CGM. The glucose sensor used was a Paradigm Veo with Enlite glucose sensor and MiniLink transmitter. The primary endpoint was the mean difference in percentage of time spent between 72 and $180 \mathrm{mg} / \mathrm{dL}(4-10 \mathrm{mmol} / \mathrm{L})$. The main secondary endpoint was severe hypoglycemia.

\section{Results}

Fifty-two patients with T1D were randomized to either CGM followed by SMBG $(n=26)$ or SMBG to CGM $(n=26)$. Time spent in normoglycemia $(72-180 \mathrm{mg} / \mathrm{dL} ; 4-10 \mathrm{mmol} / \mathrm{L})$ was higher during CGM than during SMBG: $65.0 \%$ [95\% CI $62.8 \%, 67.3 \%]$ vs. $55.4 \%[53.1 \%, 57.7 \%]$; mean difference $9.6 \%[8.0 \%, 11.2 \%](P<0.001)$. Time spent in hyperglycemia and hypoglycemia were significantly decreased in the CGM group. The number of severe hypoglycemia events were lower in the CGM group (14 events vs. 34 events, $P=0.033$ ).

\section{Conclusion}

Use of CGM in T1D patients with impaired awareness of hypoglycemia resulted in an overall increased time in normal glycemia $(72 \mathrm{mg} / \mathrm{dL}$ to $180 \mathrm{mg} / \mathrm{dL})$ with reduced time in both hyperglycemia and hypoglycemia, resulting in a significant reduction in severe hypoglycemia. These results support the use of CGM in patients with T1D who are not at goal or who have hypo unawareness or history of severe hypoglycemia.

\section{Comments}

Use of CGM is now evolving to be standard of care in managing patients with T1D, whether on an insulin pump or multiple daily injections. CGM allows patients to not only better manage their glucose in a normal glycemic range, but also to prevent both hyperglycemia and hypoglycemia and significantly reduce the risk of severe hypoglycemia, especially in people with impaired awareness to hypoglycemia. CGM should now be standard of care for management of patients with type 1 diabetes not at goal, whether it is from hyperglycemia or the risk of hypoglycemia.

\section{REPLACE-BG: a randomized trial comparing continuous glucose monitoring with and without routine blood glucose monitoring in well-controlled adults with type 1 diabetes}

Aleppo $G^{1}$, Ruedy $\mathrm{KJ}^{2}$, Riddlesworth $\mathrm{TD}^{2}$, Kruger $\mathrm{DF}^{3}$, Peters $A L^{4}$, Hirsch $I^{5}$, Bergenstal $R^{6}{ }^{6}$, Toschi $E^{7}$, Ahmann $A J^{8}$, Shah $V N^{9}$, Rickels $M R^{10}$, Bode BW $W^{11}$, Philis-Tsimikas $A^{12}$, Pop-Busui $R^{13}$, Rodriguez $H^{14}$,
Eyth $E^{14}$, Bhargava $A^{15}$, Kollman $C^{2}$, Beck $R W^{2}$; for the REPLACE-BG Study Group

${ }^{I}$ Northwestern University, Chicago, IL; ${ }^{2}$ Jaeb Center for Health Research, Tampa, FL; ${ }^{3}$ Henry Ford Health System, Detroit, MI; ${ }^{4}$ Keck School of Medicine of the University of Southern California, Los Angeles, CA; ${ }^{5}$ University of Washington School of Medicine, Seattle, WA; ${ }^{6}$ International Diabetes Center Park Nicollet, Minneapolis, MN; ${ }^{7}$ Joslin Diabetes Center, Boston, MA; ${ }^{8}$ Harold Schnitzer Diabetes Health Center at Oregon Health and Science University, Portland, OR; ${ }^{9}$ Barbara Davis Center for Childhood Diabetes, Aurora, CO; ${ }^{10}$ University of Pennsylvania Perelman School of Medicine, Philadelphia, PA; ${ }^{11}$ Atlanta Diabetes Centers, Atlanta, GA ${ }^{12}$ Scripps Whittier Diabetes Institute, La Jolla, CA; ${ }^{13}$ University of Michigan, Ann Arbor, MI; ${ }^{14}$ University of South Florida, Tampa, FL; ${ }^{15}$ Iowa Diabetes and Endocrinology Research Center, Des Moines, IA

Diabetes Care 2017; 40: 538-545

\section{Aims}

A randomized noninferiority clinical trial was conducted to determine whether a confirmatory self-measured blood glucose reading is needed to make an insulin decision for adults with well-controlled type 1 diabetes (T1D) who are on CGM.

\section{Methods}

Adults aged $\geq 18$ years (mean $44 \pm 14$ years) with T1D for $\geq 1$ year (mean duration $24 \pm 12$ years) and $\mathrm{HbA} 1 \mathrm{c} \leq 9 \%$ (mean $7.0 \pm 0.7 \%$ ) who were using an insulin pump were selected for the study; $47 \%$ were CGM users prior to the study. Subjects were randomized 2:1 to CGM-only $(n=149)$ or the CGM + BGM $(n=77)$ group. Time in range $(70$ $180 \mathrm{mg} / \mathrm{dL}$ ) for the course of the trial (26 weeks) was the primary outcome; the prespecified noninferiority limit was $7.5 \%$.

\section{Results}

Blood glucose measurement tests per day, including the two required per daily CGM calibration of the G4 Platinum Dexcom Sensor, averaged $2.8 \pm 0.9$ in the CGM-only group and $5.4 \pm 1.4$ in the CGM+BGM group $(P<0.001)$. In the CGM-only group, mean time in range $(70-180 \mathrm{mg} / \mathrm{dL})$ was $63 \pm 13 \%$ at both baseline and 26 weeks, compared with $65 \pm 13 \%$ and $65 \pm 11 \%$ at baseline and 26 weeks in the CGM + BGM group (adjusted difference is $0 \%$, one-sided 95\% CI $-2 \%$ ). There were no occurrences of severe hypoglycemia in the CGM-only group and a single occurrence in the CGM+BGM group.

\section{Conclusion}

A confirmatory BGM in addition to CGM in T1D patients well controlled on insulin pumps and CGM is not mandatory under usual circumstances to make a diabetes decision.

\section{Comments}

Per U.S. Food and Drug Administration guidelines on using CGM, all patients must check their blood glucose 
to calibrate their CGM sensor as recommended as well as checking their blood glucose whenever they make a diabetes treatment decision, such as to consume carbs for a low glucose level, to treat elevated glucose, or to change their insulin doses. However, many patients on CGM will typically use their CGM to decide how much insulin to take for food plus correction as well as to treat a low glucose level. This study confirms that it is safe for T1D patients controlled on an insulin pump with CGM to use their CGM readings to make appropriate decisions for diabetes management. However, they still need to calibrate their sensor as scheduled, and if in doubt regarding the CGM reading, they should check their blood glucose.

\section{Hypoglycemic event frequency and the effect of continuous glucose monitoring in adults with type 1 diabetes using multiple daily insulin injections}

Riddlesworth $T^{l}$, Price $D^{2}$, Cohen $N^{1}$, Beck $R W^{1}$

${ }^{1}$ Jaeb Center for Health Research, Tampa, FL;

${ }^{2}$ Dexcom, Inc., San Diego, CA

Diabetes Ther 2017; 8: 947-951

\section{Aims}

To determine the frequency of hypoglycemic events in the DIAMOND randomized clinical trial that examines the efficacy using CGM and improving glycemic control in participants using MDI.

\section{Methods}

CGM data were collected from both groups in the DIAMOND study at the beginning of the study and after 3 and 6 months. A hypoglycemic event was defined as a series of at least CGM values less than $54 \mathrm{mg} / \mathrm{dL}$ separated by $20 \mathrm{~min}$ utes or more with no intervening values of $54 \mathrm{mg} / \mathrm{dL}$ or greater. Hypoglycemic event rates were compared using a linear model adjusted for the baseline event rate per 24 hours, baseline $\mathrm{HbA1c}$, and site as a random effect.

\section{Results}

The median hypoglycemic event rate fell by $30 \%$ ( 0.23 per $24 \mathrm{~h}$ at baseline and 0.16 per $24 \mathrm{~h}$ at follow-up) in the CGM group while the median hypoglycemic rate did not change in the SMBG group $(0.31$ per $24 \mathrm{~h}$ at baseline and 0.30 per $24 \mathrm{~h}$ at follow-up; $P=0.03)$.

\section{Conclusions}

Participants with type 1 diabetes on MDI using CGM experienced a greater reduction in hypoglycemic event rate than participants receiving usual care with SMBG alone.

\section{Comments}

The use of CGM in type 1 diabetes patients suboptimally controlled on MDI will increase their time in
$70-180 \mathrm{mg} / \mathrm{dL}$ BG range, decrease time spent below $70 \mathrm{mg} / \mathrm{dL}$, as well as decrease events of hypoglycemia defined as a glucose less than $54 \mathrm{mg} / \mathrm{dL}$ lasting at least 20 minutes with no intervening values of $54 \mathrm{mg} / \mathrm{dL}$ or higher. In conclusion, CGM in patients with type 1 diabetes on MDI will not only improve their overall glycemic control but will lessen their risk of hypoglycemia, in both number of events and their duration.

\section{Continuous glucose monitoring in older adults with type 1 and type 2 diabetes using multiple daily injections of insulin: results from the DIAMOND trial}

Ruedy KJ ${ }^{1}$, Parkin $C G^{2}$, Riddlesworth $T D^{1}$, Graham $C^{3}$; for the DIAMOND Study Group

${ }^{1}$ Jaeb Center for Health Research, Tampa, FL; ${ }^{2}$ CGParkin Communications, Inc., Boulder City, NV; ${ }^{3}$ Dexcom, Inc., San Diego, CA

\section{J Diabetes Sci Technol 2017; 11: 1138-1146}

\section{Aims}

To determine the effectiveness of real-time CGM in older adults (age $\geq 60$ years) with type 1 diabetes (T1D) or type 2 diabetes (T2D) and HbA1c of $7.5-10.0 \%$ who are using multiple daily injections (MDI).

\section{Methods}

The DIAMOND trial was a multicenter randomized trial conducted in the United States and Canada in 116 individuals $\geq 60$ years (mean $67 \pm 5$ years), with 34 participants having T1D and 82 having T2D, all using MDI therapy, who were randomly assigned to either CGM $(n=63)$ or continued management with SMBG $(n=53)$. The primary outcome was HbA1c measured at 24 weeks compared with baseline in both groups.

\section{Results}

The CGM group exhibited greater $\mathrm{HbA} 1 \mathrm{c}$ reduction from baseline to 24 weeks than did the SMBG group $(-0.9 \pm 0.7 \%$ vs. $-0.5 \pm 0.7 \%$, adjusted difference in mean change was $-0.4 \pm 0.1 \% ; P<0.001)$. CGM-measured glycemic variability $(P=0.02)$ and time $>250 \mathrm{mg} / \mathrm{dL}(P=0.006)$ were also lower in the CGM group. A total of 61 subjects in the CGM group completed the trial. Of those, $97 \%$ used CGM $\geq 6$ days/week in month 6 . Neither group reported any severe diabetic ketoacidosis or hypoglycemic events.

\section{Conclusions}

Older adults ( $\geq 60$ years) with T1D and T2D and on MDI benefited from using CGM, with improved glycemic control measured by change in HbA1c and time spent $>250 \mathrm{mg} / \mathrm{dL}$ with a reduction in glycemic variability. CGM should be considered for older adults with T1D and T2D who are on MDI and not at goal. 


\section{Comments}

CGM is now standard of care for all individuals who have type 1 and type 2 diabetes who are not controlled on MDI or CSII regardless of age. As shown in the current study, CGM has been shown to improve HbA1c, if elevated, with greater time in normal range $(70-180 \mathrm{mg} / \mathrm{dL})$ and less time above or below range as well as a reduction in glycemic variability. A high percentage of study participants in the DIAMOND study used CGM on a daily and near-daily basis over the 6 months with limited number of visits or phone calls and no contact after 3 months.

\section{Effect of initiating use of an insulin pump in adults with type 1 diabetes using multiple daily insulin injections and continuous glucose monitoring (DIAMOND): a multicentre, randomised controlled trial}

Beck $R W^{1}$, Riddlesworth $T D^{l}$, Ruedy $K J^{1}$, Kollman $C^{l}$, Ahmann $\mathrm{AJ}^{2}$, Bergenstal $\mathrm{RM}^{3}$, Bhargava $\mathrm{A}^{4}$, Bode $B W^{5}$, Haller $S^{6}$, Kruger $D^{7}{ }^{7}$, McGill $\mathrm{JB}^{8}$, Polonsky $W^{9}$, Price $D^{10}$, Toschi $E^{11}$; for the DIAMOND Study Group

${ }^{1}$ Jaeb Center for Health Research, Tampa, FL; ${ }^{2}$ Oregon Health and Science University, Portland, OR; ${ }^{3}$ Park Nicollet Institute International Diabetes Center, Minneapolis, $M N ;{ }^{4}$ Iowa Diabetes and Endocrinology Research Center, Des Moines, IA; ${ }^{5}$ Atlanta Diabetes Associates, Atlanta, GA; ${ }^{6}$ Diabetes and Glandular Disease Clinic, San Antonio, TX; ${ }^{7}$ Henry Ford Medical Center Division of Endocrinology, Detroit, MI, ${ }^{8}$ Division of Endocrinology, Metabolism and Lipid Research Washington University in St. Louis, St. Louis, MO; ${ }^{9}$ Behavioral Diabetes Institute, San Diego, CA; ${ }^{10}$ Dexcom, San Diego, CA; ${ }^{11}$ Joslin Diabetes Center, Boston, $M A$

Lancet Diabetes Endocrinol 2017; 5: 700-708

This manuscript is also discussed in the article on Insulin Pumps, page S-30.

\section{Aims}

A multicenter trial was conducted to assess glycemic outcomes when switching from multiple daily injections (MDI) to CSII in adults with type 1 diabetes currently using CGM.

\section{Methods}

A multicenter trial was conducted in 75 adults with type 1 diabetes. The CGM group of the DIAMOND trial were randomly assigned to continue MDI $(\mathrm{n}=38)$ or switch to CSII $(n=37)$ with continuation of CGM for 28 weeks. The primary outcome was CGM-measured time in the glucose range of $70-180 \mathrm{mg} / \mathrm{dL}(3.9-10.0 \mathrm{mmol} / \mathrm{L})$.

\section{Results}

Overall, 36 (97\%) of 37 participants in the CGM plus CSII and 35 (92\%) of the 38 participants in the CGM plus MDI group completed the study. Mean CGM use with MDI was 6.7 days per week and mean CGM use with CSII was 6.9 days $(P=0.86)$. Over the 28 -week follow-up period, mean time in target glucose concentration range $(70-180 \mathrm{mg} / \mathrm{dL})$ was $791 \mathrm{~min} /$ day in the CGM plus CSII group and $741 \mathrm{~min} /$ day in the CGM plus MDI group (adjusted mean treatment group difference $83 \min$ [95\% CI 17, 149]; $P=0.01$ ). In the CGM plus CSII group, CGM-measured mean glucose $(P=0.005)$ and hyperglycemia were reduced on four metrics: $>180 \mathrm{mg} / \mathrm{dL}$ $(P=0.007) ;>250 \mathrm{mg} / \mathrm{dL}(P=0.02) ;>300 \mathrm{mg} / \mathrm{dL}(P=0.004)$; and area under the curve of $180 \mathrm{mg} / \mathrm{dL}(P=0.02)$. The CGM plus CSII group had an increase, however, in CGM-measured hypoglycemia less than $70 \mathrm{mg} / \mathrm{dL}(P=0.001),>60 \mathrm{mg} / \mathrm{dL}$ $(P=0.002)$, and $>50 \mathrm{mg} / \mathrm{dL}(P=0.009)$ and area under the curve for $70 \mathrm{mg} / \mathrm{dL}(P=0.002)$. From baseline to 28 weeks, mean $\mathrm{HbA} 1 \mathrm{c}$ change in the CGM plus CSII group was $0.3 \%$ and in the CGM plus MDI group it was $0.1 \%(P=0.32)$. Three severe events were reported: hypoglycemia $(n=1)$ in the CGM plus MDI group and diabetic ketoacidosis $(n=1)$ and severe hypoglycemia $(n=1)$ occurred in the CGM plus CSII group.

\section{Conclusions}

Glycemic control measured by time in the glucose range of $70-180 \mathrm{mg} / \mathrm{dL}$ is improved by initiation of CSII in adults with type 1 diabetes on CGM using MDI. Biochemical hypoglycemia, however, was increased in the CSII patients compared with the MDI patients on CGM. There was no significant difference in HbA1c between these two groups.

\section{Comments}

This is one of the first studies looking at patients with type 1 diabetes on MDI with CGM undergoing a randomized intervention of staying on MDI with CGM or changing to CSII with CGM. Time in glucose range of $70-180 \mathrm{mg} / \mathrm{dL}$ was improved in the patients initiating CSII with less time spent above $180 \mathrm{mg} / \mathrm{dL}$. However, biochemical hypoglycemia defined by four separate measures was increased in the CSII CGM group. Reasons for the increase in the hypoglycemia are unknown. Prior studies on patients transferring from MDI to CSII usually show a marked reduction in biochemical hypoglycemia and duration of hypoglycemia as well as a reduction in severe hypoglycemia events. Further studies are needed to assess whether glycemic control can be improved without an increase in hypoglycemia when transferring from MDI with CGM to CSII with CGM.

\section{"Let the algorithm do the work": reduction of hypoglycemia using sensor-augmented pump therapy with predictive insulin suspension (SmartGuard) in pediatric type 1 diabetes patients}

Biester $T^{l}$, Kordonouri $O^{l}$, Holder $M^{2}$, Remus $K^{l}$, Kieninger-Baum $D^{3}$, Wadien $T^{2}$, Danne $T^{l}$

${ }^{1}$ AUF DER BULT, Children's Hospital, Hannover, Germany; ${ }^{2}$ Klinikum Stuttgart, Olgahospital, Stuttgart, Germany; ${ }^{3}$ Universitätsmedizin Mainz, Zentrum für Kinder- und Jugendmedizin, Mainz, Germany

Diabetes Technol Ther 2017; 19: 173-182

This manuscript is also discussed in the article on Insulin Pumps, page S-30. 


\section{Aims}

Hypoglycemia represents a burden to people with T1D and induces hypoglycemia anxiety. Metabolic effects of hypoglycemia caused by counter-regulatory hormones further impede the achievement of good glycemic control. This study investigated the effect of a predictive low glucose suspend (PLGS) algorithm (SmartGuard) in a pediatric population with T1D, prone to hypoglycemia.

\section{Methods}

This outpatient, nonrandomized, prospective multicenter observational trial conducted over 2 months at three centers included 24 participants with T1D for at least 1 year, were between 1 and 21 years old, and had been using insulin CSII for at least 3 months. The primary endpoint was the comparison of mean values for area under the curve (AUC) per day in the hypoglycemic area $<70 \mathrm{mg} / \mathrm{dL}(<3.9 \mathrm{mmol} / \mathrm{L})$ during sensor-augmented insulin pump (SAP) (Medtronic 640G System, Northridge, CA) use with or without the predictive low glucose management (PLGM; SmartGuard) algorithm. The secondary outcome parameters were time spent in hypoglycemia per day (values $<70 \mathrm{mg} / \mathrm{dL}[<3.9 \mathrm{mg} / \mathrm{dL}$ ] and $<40 \mathrm{mg} / \mathrm{dL}[<2.2 \mathrm{mg} / \mathrm{dL}])$. In addition, the number of PLGM activations per day, the average time of insulin suspension, the glucose nadirs, and glucose values upon suspension and after resuming insulin delivery were investigated. Three consecutive phases followed the initial training: (i) a 4-week introduction and dose optimization period for patients to become familiar with the device (CSII only, no CGM); (ii) a 2-week phase 1 period using SAP (CSII and CGM) without activating either PLGS or the low-glucose suspend (LGS) features, the alert level for hypoglycemia was set to $70 \mathrm{mg} / \mathrm{dL}(3.9 \mathrm{mmol} / \mathrm{L})$; and (iii) a 6 -week phase 2 period during which patients used SAP therapy with PLGM (SAP + SmartGuard). The threshold for PLGS ("suspend before low") was set to $70 \mathrm{mg} / \mathrm{dL}(3.9 \mathrm{mmol} / \mathrm{L})$ and the "alert before low" alarm was silenced. The hypoglycemia alert was set to $70 \mathrm{mg} / \mathrm{dL}(3.9 \mathrm{mmol} / \mathrm{L})$.

\section{Results}

A comparison of the phases with and without PLGS was possible for 18 of the 24 patients, since 5 patients accidentally activated the LGS function (a protocol violation). The primary outcome, AUC area $<70 \mathrm{mg} / \mathrm{dL}$, decreased from $0.76 \pm 0.73 \mathrm{mg} / \mathrm{dL} \cdot$ day without PLGS to $0.38 \pm 0.24 \mathrm{mg} /$ $\mathrm{dL} \cdot$ day with PLGS $(P=0.027)$. Correspondingly, the time spent $<70 \mathrm{mg} / \mathrm{dL}$ decreased significantly with PLGS use from $73 \pm 56$ to $31 \pm 22 \mathrm{~min}$ per day $(P=0.003)$. The rate of hypoglycemic events $<70 \mathrm{mg} / \mathrm{dL}$ was lower during PLGS use: $1.02 \pm 0.52$ without PLGS compared with $0.72 \pm 0.36$ with PLGS $(P=0.027)$, and $<40 \mathrm{mg} / \mathrm{dL} 0.20 \pm 0.22$ compared with $0.10 \pm 0.10$, respectively $(P=0.038)$. No severe hypoglycemia requiring external assistance occurred. The significant reduction in hypoglycemia was accompanied by a nonsignificant increase in mean sensor glucose concentration from $171 \pm 26$ without to $180 \pm 19 \mathrm{mg} / \mathrm{dL}$ with PLGS, and a slight increase in HbA1c from $7.5 \pm 0.5 \%$ ( $58.2 \pm 7.6 \mathrm{mmol} /$ $\mathrm{mol} \mathrm{Hb})$ to $7.6 \pm 0.7 \%(59.0 \pm 7.1 \mathrm{mmol} / \mathrm{mol} \mathrm{Hb})$, respectively. Time in range $(70-180 \mathrm{mg} / \mathrm{dL})$ was not changed with PLGS (SAP $793 \pm 177 \mathrm{~min} ; 55.1 \%$ vs. PLGS $794 \pm 175 \mathrm{~min}$;
$54.9 \%)$. Although the mean glucose values at PLGS activation $(105 \pm 8 \mathrm{mg} / \mathrm{dL})$ and subsequent resumption $(103 \pm 11 \mathrm{mg} /$ dL) of insulin delivery were almost equivalent, values $1 \mathrm{~h}$ after resumption of insulin infusion showed higher average glucose values of $162.0 \pm 15.1 \mathrm{mg} / \mathrm{dL}$. Although similar glucose concentrations at insulin suspension and resumption were recorded, carbohydrates ( $\mathrm{CHO}$ ) intake significantly influenced glucose values $1 \mathrm{~h}$ after resumption of insulin infusion $(190.8 \pm 26.5 \mathrm{mg} / \mathrm{dL}$ with $\mathrm{CHO}$ intake vs. $138.7 \pm 10.3 \mathrm{mg} / \mathrm{dL}$ without $\mathrm{CHO}$ intake; $\mathrm{P}<0.001)$. Glucose values $1 \mathrm{~h}$ after resumption of insulin infusion were also significantly higher during the day $(174.4 \pm 17.7 \mathrm{mg} /$ dL) versus night $(137.3 \pm 13.8 \mathrm{mg} / \mathrm{dL} ; P<0.001)$, when $\mathrm{CHO}$ intake during sleep is less likely.

\section{Conclusions}

Significant decreases in both intensity and duration of hypoglycemic events were observed with the use of PLGS, along with significantly lower frequency of hypoglycemic events. However, to prevent excessive rise in glucose levels after insulin suspension, patients and families need counseling to trust the PLGS algorithm, and educated that combining manual resumption of insulin with oral $\mathrm{CHO}$ intake should generally be discouraged as it often results in excessive postsuspension elevations of glucose levels.

\section{Comments}

This interesting study was the first to raise awareness on the interaction between an automated algorithm and its user during routine use. It confirms that the PLGS algorithm works efficiently, and it provides some initial evidence that it may work better without any interference from its user. Once again, proper training of the user for efficient use of any novel technology, PLGS in this case, seems paramount (12). However, this training will become increasingly detailed: the more sophisticated and independent the algorithm, the less intervention required from patients, but also the more crucial when needed. This study stresses that the user of the PLGS and their family need counseling to trust the algorithm and "let it do the work," unless, however, there is reasonable doubt the PLGS can succeed because of, for example, too much active insulin on board, or increased insulin sensitivity due to augmented physical activity, or excessive alcohol intake. Therefore, standard recommendations given to people with T1D will not apply any more. All health-care professionals will need comprehensive understanding of novel automated algorithms in order to provide efficient counseling and training to the users and their families.

\section{Prevention of hypoglycemia with predictive low glucose insulin suspension in children with type 1 diabetes: a randomized controlled trial}

Battelino $T^{1,2}$, Nimri $R^{3}$, Dove $K^{1}$, Phillip $M^{3,4}$, Bratina $N^{1}$

${ }^{I}$ Department of Pediatric Endocrinology, Diabetes and Metabolism, University Medical Centre-University Children's 
Hospital, Ljubljana, Slovenia; ${ }^{2}$ Faculty of Medicine, University of Ljubljana, Ljubljana, Slovenia; ${ }^{3}$ The Jesse $Z$ and Sara Lea Shafer Institute for Endocrinology and Diabetes, National Center for Childhood Diabetes, Schneider Children's Medical Center, Petah Tikva, Israel; ${ }^{4}$ Sackler Faculty of Medicine, Tel Aviv University, Tel Aviv, Israel

Diabetes Care 2017; 40: 764-770

This article is also discussed in the article on Insulin Pumps, page S-30, and the article on Diabetes Technology and Therapy in the Pediatric Age Group, page S-114.

\section{Aims}

Low glucose suspend (LGS) reduces hypoglycemia in randomized controlled trials. Predictive low glucose suspend (PLGS) or management (PLGM) may further prevent hypoglycemia. In this randomized study, the number of hypoglycemic events was investigated in a pediatric population with T1D using a sensor augmented pump (SAP) with PLGM turned on or PLGM turned off.

\section{Methods}

This randomized, two-arm, parallel, controlled, open-label study, conducted at two clinical sites, included patients aged between 8 and 18 years, T1D for $>12$ months, treated by CSII with or without CGM for $>3$ months, with screening HbA1c $<10 \%(<86 \mathrm{mmol} / \mathrm{mol})$, and no use of the LGS feature during the last 2 weeks prior to inclusion. After 640G device (Medtronic, Northridge, CA) related training and a 3day run-in, participants were randomly assigned to either the intervention (PLGM feature turned on) or the control (PLGM feature turned off) group for 2 weeks. Audible alarms were turned off for all. Insulin pump settings were set and adjusted individually as appropriate for each patient. The primary endpoint was the number of hypoglycemic events below $65 \mathrm{mg} / \mathrm{dL}(3.6 \mathrm{mmol} / \mathrm{L})$, based on sensor glucose (SG) readings, with a minimum duration of $20 \mathrm{~min}$ and each separated by a minimum of $30 \mathrm{~min}$.

\section{Results}

A total of 100 patients were enrolled (50 per site). Two patients discontinued the study, and two were excluded from statistical analysis due to lack of sensor data, so the final analysis included 47 patients from PLGM ON and 49 from the PLGM OFF group $(n=96)$. There was a significant difference between the PLGM ON vs. PLGM OFF in number of hypoglycemic events $<65 \mathrm{mg} / \mathrm{dL}(3.6 \mathrm{mmol} / \mathrm{L})$, based on $\mathrm{SG}$ readings during 2 weeks (mean $\pm \mathrm{SD} 4.4 \pm 4.5$ and $7.4 \pm 6.3$, respectively; $P=0.008)$, also when calculated separately for night $(P=0.025)$ and day $(P=0.022)$. The number of hypoglycemic events $<70 \mathrm{mg} / \mathrm{dL}(3.9 \mathrm{mmol} / \mathrm{L})$ and $<60 \mathrm{mg} / \mathrm{dL}$ $(3.3 \mathrm{mmol} / \mathrm{L})$ was significantly lower in the PLGM ON group $(P=0.001$ and 0.013 , respectively), also when calculated separately for day and night. Time spent $<65 \mathrm{mg} / \mathrm{dL}(3.6 \mathrm{mmol} / \mathrm{L})$, $<60 \mathrm{mg} / \mathrm{dL}(3.3 \mathrm{mmol} / \mathrm{L})$, and $<50 \mathrm{mg} / \mathrm{dL}(2.8 \mathrm{mmol} / \mathrm{L})$ was significantly shorter in the PLGM ON group $(P=0.0106,0.089$, and 0.0203 , respectively). Time spent $>140 \mathrm{mg} / \mathrm{dL}(7.8 \mathrm{mmol} /$ L) was significantly longer in the PLGM ON group $(P=0.0165)$, while time spent $>180 \mathrm{mg} / \mathrm{dL}(10 \mathrm{mmol} / \mathrm{L})$ and $>250 \mathrm{mg} / \mathrm{dL}$ $(13.9 \mathrm{mmol} / \mathrm{L})$ was not different between the two groups. No serious adverse events, episodes of diabetic ketoacidosis, or serious adverse device-related events were reported.

\section{Conclusions}

The use of PLGM insulin suspension was associated with a significantly reduced number of hypoglycemic events and time spent in hypoglycemia. Although this was achieved at the expense of increased time in moderate hyperglycemia, there were no serious adverse effects in young participants with T1D.

\section{Comments}

This is the first randomized, controlled trial with PLGS/ PLGM technology. Its primary outcome-number of hypoglycemic events-has a direct relevance for routine clinical practice, particularly as the significant difference was achieved in a short period of 2 weeks in a predominantly adolescent population with regular physical activity. Several new observational trials confirmed the efficacy of the PLGS/PLGM technology, also after prolonged physical activity in adults (13) and in children (14). The use of PLGS/PLGM technology is often associated with prolonged time in mild/moderate hyperglycemia. It is proposed that this may be related to overtreatment with rescue carbohydrates. As discussed previously, every user has to climb the learning curve and put some trust in the technology but also understand its current shortcomings and stay vigilant. Further technological development of PLGM toward a hybrid closed loop system brings even more efficacy and safety; however, balanced judgment based on solid education and training is still needed when adverse circumstances override the capabilities of automated algorithms.

\section{Schooling diabetes: use of continuous glucose monitoring and remote monitors in the home and school settings}

Erie $C^{1}$, Van Name $M A^{2}$, Weyman $K^{2}$, Weinzimer $S A^{2}$, Finnegan $J^{2}$, Sikes $K^{2}$, Tamborlane $W V^{2}$, Sherr $J L^{2}$

${ }^{I}$ Charles E. Schmidt College of Medicine, Florida Atlantic University, Boca Raton, FL; ${ }^{2}$ Department of Pediatrics, Yale School of Medicine, New Haven, CT

Pediatr Diabetes 2017 Mar 17. [Epub ahead of print] DOI 10.1111/pedi.12518

This article is also discussed in the article on Diabetes Technology and Therapy in the Pediatric Age Group, page S-114.

\section{Aims}

The psychological distress experienced by caregivers of children with T1D striving to succeed in keeping their child's glucose in near-normal range often negatively affects the family's quality of life, despite the availability of novel technologies. This study investigated real-time and remote CGM practices at home and in schools, attitudes towards its use, and the expectations of parents and caregivers related to its use. 


\section{Methods}

Parents of pediatric patients with T1D at Yale University Medical School were invited to the study and asked to complete a survey assessing the use of CGM devices and remote monitoring as well as their reasons, goals, attitudes, and expectations of CGM use. A separate survey was distributed to the child's daytime caregiver (i.e., school nurse, daycare teacher, and nanny) by participants. Open and truthful responses were encouraged by the anonymity of the surveys, which were returned directly to the research team using prepaid envelopes and/or anonymous boxes. Fifteen multiple choice questions in parent surveys collected information regarding CGM use, alert settings and responses, frequency of real-time and retrospective sensor glucose review, and expectations of daytime caregivers. Nine open response questions assessed parents' reasons for and goals of CGM use and feelings regarding both CGM use and remote monitoring. Daytime caregiver surveys collected data on alert responses, frequency of visualizing CGM trends, and use of remote monitoring with 10 multiple choice questions; additionally, 8 open response questions asked them to describe their responsibilities regarding CGM alerts, tracings, and T1D management decisions, as well as their overall feelings about CGM and remote monitoring. Comfort using CGM technology was assessed using a 10 -point Likert scale $(1=$ not at all comfortable, $10=$ extremely comfortable).

\section{Results}

Out of 57 distributed survey pairs, 33 parent surveys and 17 daytime caregiver surveys were returned. Twenty-one parents cared for elementary school age children $(\leq 10$ years) and 11 cared for middle or high school age (11-17 years) youth. Thirty-two patients wore Dexcom G4 or G5 sensors (Dexcom, Inc., San Diego, CA) and 1 patient wore a Medtronic Enlite Sensor (Medtronic, Inc., Northridge, CA), with overall frequency of sensor use for 7 days a week at $94 \%$. The duration of CGM use ranged from 2 weeks to 7 years (mean 1.78 years). Twenty-three $(68 \%)$ of the parents reported using remote monitoring, which was more common in elementary school children (age $\leq 10$ years) $(81 \%)$ than in children older than 10 years $(50 \%)$. The use of threshold alerts was nearly two times more common than rate of change alerts, also with remote monitoring. Both parents and daytime caregivers typically responded to high and low-glucose alerts with checking the self-monitored blood glucose (SMBG) before treating. However, 39\% of parents and $35 \%$ of caregivers reported they also treated lows without SMBG, depending on the signs and symptoms. A good one-third of daytime caregivers reported contacting the child's parent if a low- or high-glucose alert occurred. The CGM data were primarily used in real-time, with $56 \%$ of parents reporting checking the remote monitor at least hourly. Only 38\% reported retrospective review of uploaded data more than quarterly. Eighty-five percent of parents expected their child's daytime caregiver to respond to CGM alerts, and $61 \%$ felt the caregiver should use the CGM data to make decisions. Two-thirds $(65 \%)$ of parents indicated that they wanted their child's caregiver to be in contact with them in responding to CGM alerts. Eighty-nine percent of daytime caregivers felt the parents' expectations on how they should use CGM data were reasonable. All parents and $78 \%$ of caregivers reported that use of the system decreased their worry or stress. Daytime caregivers reported an average comfort level of 7.8 (range 5-10) on a 10 -point Likert scale. The median number of children to daytime caregivers was reported to be 455 (interquartile range: 301,611$)$. There was no significant relationship between CGM comfort and number of children to daytime caregiver, nor the age of the child. Replies to open questions revealed overall positive feelings and satisfaction with CGM in both groups.

\section{Conclusions}

The results of this study were limited by its small sample size and response rate of $58 \%$ among parents and one-third of daytime caregivers, therefore a bias toward positive responses could not be excluded. The positive and cooperative management reported by parents and daytime caregivers strongly supports the important role of CGM in the routine management of children with T1D both at home and in school.

\section{Comments}

This behavioral report is important despite several potential biases, including those related to small sample size, limited response rate (particularly for daytime caregivers), single center, and very high sensor use. Therefore, results cannot be generalized to most pediatric populations with T1D. However, this report provides an excellent example of how CGM can work for the benefit of all involved-children with T1D, their families, and their daytime caregivers in schools and kindergartens. Considerable stress in families that have small children with T1D is well documented (15) and the organization of a collaborative and integrated diabetes care inside the medical center, at home, and in the kindergarten/school environment is of crucial importance (16). The medical benefits of CGM are now beyond reasonable doubt; however, its successful integration into day-to-day diabetes management is yet to be achieved, and larger longitudinal behavioral studies are needed.

\section{Striving for control: lessons learned from a successful international Type 1 Diabetes Youth Challenge}

Kordonouri $O^{1}$, Vazeou $A^{2}$, Scharf $M^{3}$, Würsig $M^{1}$, Battelino $T^{4,5}$; for the SWEET Group

${ }^{1}$ Diabetes Center for Children and Adolescents, Children's Hospital AUF DER BULT, Hannover, Germany; ${ }^{2} P \& A$ Kyriakou Children's Hospital, Athens, Greece; ${ }^{3}$ Centro de Diabetes Curitiba, Division of Pediatric Endocrinology os Hospital Nossa Senhora Das Gracias, Curitiba, Brazil; ${ }^{4}$ Department of Endocrinology, Diabetes and Metabolic Diseases, University Children's Hospital, Ljubljana, Slovenia; ${ }^{5}$ Faculty of Medicine, University of Ljubljana, Ljubljana, Slovenia

Acta Diabetologica 2017; 54: 403-409 


\section{Aims}

The SWEET e.V. Initiative, a network of Centers of Reference for improving the management of diabetes in children and young people, initiated the idea of organizing a physical challenge for youngsters with T1D. The aim of the initiative was to demonstrate that well-trained participants using modern insulin treatments are able to effectively complete even exceptional physical challenges without limitations related to their diabetes.

\section{Methods}

The challenge combined a long-distance trek of different intensities from sea-level to $2080 \mathrm{~m}, 54.5 \mathrm{~km}$, in 4 days. The participants were asked to wear a CGM (MiniMed Medtronic, Northridge, CA, or DexCom G4 Platinum, Dexcom, San Diego, CA) during the challenge and use it for diabetes management. Low CGM alert was set at $90 \mathrm{mg} / \mathrm{dL}$ $(5.0 \mathrm{mmol} / \mathrm{L})$ during the day and at $60 \mathrm{mg} / \mathrm{dL}(3.3 \mathrm{mmol} / \mathrm{L})$ during the night. High CGM alerts were set at $250 \mathrm{mg} / \mathrm{dL}$ (13.9 mmol/L) all day. The glycemic target during trekking was defined as $80-180 \mathrm{mg} / \mathrm{dL}(4.4-10.0 \mathrm{mmol} / \mathrm{L})$. In case of hypoglycemia or a rapid decrease of glucose levels ( $>2 \mathrm{mg}$ / $\mathrm{dL} \cdot \min )$, participants took $15 \mathrm{~g}$ of dextrose and waited for 15 min. Two adult participants with T1D experienced in similar challenges acted as mentors to the young participants. Four physicians and one nurse/educator participated as the medical team.

\section{Results}

In total, 5 female and 6 male participants $(\mathrm{N}=11$; age $18.2 \pm 1.3$ years, T1D duration $7.9 \pm 3.5$ years, BMI $21.6 \pm$ $1.6 \mathrm{~kg} / \mathrm{m}^{2}, \mathrm{HbA} 1 \mathrm{c} 7.3 \pm 0.7 \%(56 \pm 16 \mathrm{mmol} / \mathrm{mol})$ mean \pm $\mathrm{SD})$ were included in the challenge. Five individuals $(2$ males, 3 females) were on CSII, and 6 were on multiple daily injections (MDI) using glargine and insulin lispro $(n=2)$ or insulin aspart $(n=4)$. Ten adjusted their prandial insulin by counting carbohydrates. Insulin requirements decreased by $31.1 \pm 16.7 \% \quad(P<0.001)$, basal insulin by $29.2 \pm 15.1 \%(P<0.001)$, and prandial insulin by $33.2 \pm$ $26.7 \%(P=0.013)$ during the challenge. The decrease in prandial insulin requirements during the challenge was inversely associated with pulse rate at resting conditions $(\mathrm{R}=-0.615, P=0.044)$. The mean glucose was $169.9 \pm$ $24.2 \mathrm{mg} / \mathrm{dL}$ (range 140.0-209.3 mg/dL), whereas $59.6 \pm$ $21.6 \%$ of CGM values were in the target range $(6.0 \pm 6.4 \%$ under $80 \mathrm{mg} / \mathrm{dL}$ and $36.9 \pm 18.4 \%$ above $180 \mathrm{mg} / \mathrm{dL})$, without a single episode of severe hypoglycemia. Hypoglycemic events $<50 \mathrm{mg} / \mathrm{dL}(2.8 \mathrm{mmol} / \mathrm{L})$ occurred in 4 participants during the night before the challenge, in 3 during the first night, and in none during the second through fourth nights $(P=0.01)$.

\section{Conclusions}

The results of this initiative demonstrate that well-trained adolescents and young adults with T1D using CGM can successfully complete exceptional physical challenges without restrictions related to their diabetes and without diabetes-related acute complications.

\section{Comments}

This observation reports very reasonable metabolic control without any acute complications during a 4-day physically challenging mountain trek. Several practical messages are noteworthy: there was 30\% decrease in average total daily insulin requirement; as basal heart rate increased, the decrease in prandial insulin requirement got smaller-which could be related to the level of physical fitness; $60 \%$ of CGM values were within the target range; and nocturnal hypoglycemia $<50 \mathrm{mg} / \mathrm{dL}$ was prevented after the first night. These results were achieved with the continuous use of CGM. As physical activity continues to be one of the pillars of healthy lifestyle for people with T1D, such a report conveys a very strong message of safety, feasibility, and success. T1D is a barrier or restriction for sport no more.

\section{Retinal neurodegeneration in patients with type 1 diabetes mellitus: the role of glycemic variability}

Picconi $F^{1,2}$, Parravano $M^{3}$, Ylli $D^{1,2}$, Pasqualetti $P^{4}$, Coluzzi $S^{1,2}$, Giordani $I^{1,2}$, Malandrucco $I^{1,2}$, Lauro $D^{1}$, Scarinci $F^{3}$, Giorno $P^{3}$, Varano $M^{3}$, Frontoni $S^{1,2}$

${ }^{1}$ Department of Systems Medicine, University of Rome Tor Vergata, Rome, Italy; ${ }^{2}$ Unit of Endocrinology, Diabetes and Metabolism, S. Giovanni Calibita Fatebenefratelli Hospital, Rome, Italy; ${ }^{3}$ IRCCS-G.B. Bietti Foundation, Rome, Italy; ${ }^{4}$ Service of Medical Statistics and Information Technology, Fatebenefratelli Foundation for Health Research and Education, AFaR Division, Rome, Italy

Acta Diabetol 2017; 54: 489-497

\section{Aims}

Hyperglycemia activates biochemical pathways, leading to tissue damage clinically described as diabetic retinopathy. Glycemic variability $(\mathrm{GV})$ is associated with the development of diabetic macrovascular and cerebrovascular complications. Retinal neurodegeneration precedes microvascular injury and may be related to $\mathrm{GV}$. The aim of this study was to investigate the effect of glycemic load and GV on structural changes of neurosensory retina in individuals with T1D, with no (noDR) or mild nonproliferative diabetic retinopathy (NPDR) and without other microvascular complications (peripheral neuropathy or microalbuminuria).

\section{Methods}

A total of 37 participants with T1D (age 18-75 years, on CSII or multiple daily injections (MDI)) consisted of 19 participants in noRD group and 18 participants in NPDR group. There were several exclusion criteria: symptomatic diabetic polyneuropathy, abnormal amplitude latency or conduction velocity in a motor nerve, a Michigan Diabetes Neuropathy Instruments score $\geq 2$ points, microalbuminuria (urinary albumin/creatinine ratio $>30 \mathrm{mg} / \mathrm{g}$ ), spherical refractive error $> \pm 6$ diopters, astigmatism (cyl) $> \pm 3$ diopters, active or past retinal pathologies, diagnosis of glaucoma or ocular hypertension, opacities of optical media that could influence functional and structural retinal testing, and history of ocular surgery. Thirteen healthy participants, without history of ocular disease or any relevant 
systemic disease, were enrolled as control group (C). A 72-h CGM (Ipro2 System, Medtronic, Northridge, CA) was performed in all participants with T1D. CGM was applied on the same day as spectral domain optical coherence tomography (SDOCT) analysis. The following indexes of GV were calculated: standard deviation (SD); mean amplitude of glucose excursion (MAGE); J-index; mean absolute glucose (MAG); continuous overall net glycemic action (CONGA-1, -2 and -4); low blood glucose (LBGI) and high blood glucose index (HBGI); and $\mathrm{M}$ value. Color stereoscopic fundus photographs were taken after an adequate dilatation by a trained photographer. Diabetic retinopathy was graded as noDR and as NPDR by two independent experienced graders. SD-OCT scanning was performed using Heidelberg Spectralis version 1.9.10.0 (Heidelberg Engineering, Heidelberg, Germany). The Spectralis segmentation software was used to obtain individual retinal layer thickness measurements including: overall retinal thickness (RT), retinal nerve fiber layer (RNFL), ganglion cell layer (GCL), inner plexiform layer (IPL), inner nuclear layer (INL), outer plexiform layer (OPL), outer nuclear layer (ONL), retinal pigment epithelium (RPE), inner retinal layer (IRL) and photoreceptor layer (PR) thickness. Measurements of mean of subfoveal, inner and outer nasal $(\mathrm{N}) /$ temporal $(\mathrm{T})$ /superior (S)/inferior (I) quadrants for individual layer were also calculated. No manual adjustments to B-scan retinal layer segmentation were used prior to measurements.

\section{Results}

Both T1D groups had reduced RNFL-N thickness vs. C group ( -3.9 for noDR and -4.9 for NPDR), with no difference between them $(-1.0)$, rendering RNFL thickness significantly dependent on quadrant $(\mathrm{F}(6 ; 132)=2.315 ; P=0.037)$. INL (INL-G), defined as the average value of the INL thickness of the four quadrants, was significantly different in the three groups $(\mathrm{F}(2,44)=3.468 ; P=0.039)$, due to larger thickness in noDR group versus $\mathrm{C}$ (mean difference $=7.73$ [95\% CI 0.32 , $15.14] ; P=0.043$ ), as well as in NPDR group versus $C$ (mean difference $=7.74[95 \%$ CI $0.33,15.15] ; P=0.043$ ), without a difference between noDR and NPDR groups $(P=0.997)$. Adding age, BMI, and HDL cholesterol (significantly different among the three groups) as covariates did not change the above results. The percentage of patients with both increase in INL-G thickness and decrease in RNFL-N thickness versus the average values of $\mathrm{C}$ group was $53 \%$ for noDR group and $28 \%$ for NPDR group. No correlation between HbA1c and retinal macular layers thickness was observed. A negative correlation was observed between LBGI and RNFL-N quadrant ( $r=$ $-0.382, P=0.034)$; a positive correlation was observed between CONGA-1, -2 and -4 and INL-G $(r=0.40, P=0.025$; $r=0.39, P=0.031 ; r=0.41, P=0.021$, respectively). Triglycerides were positively and significantly correlated to INL-G ( $r=0.48, P=0.011$ ). No differences were observed between noDR and NPDR groups. In multivariate regression analysis, $\mathrm{GV}$, and triglycerides were both independent predictors of increased INL-G thickness.

\section{Conclusion}

The present results support the concept of GV having an early neurodegenerative effect on the retina, which occurs already at a minimal vascular component of DR.

\section{Comments}

Neurodegenerative effects of diabetes on retina is extensively studied but as yet not completely elucidated. Although the detrimental effect of high blood glucose is demonstrated on different layers and specific cellpopulations of neuroretina, the process seems to be highly dynamic, and different stages present with sometimes inverse morphological presentation. Recently, retinal neurodegeneration has been associated with glycemic variability (GV) (17) and the present study extends and confirms these results. GV is also associated with peripheral neuropathy (18); however, it is still not clear whether the damage is direct or through antecedent microvascular damage. Results from the present study add to the mounting evidence that $\mathrm{GV}$ is an independent predictor of chronic complications of T1D and T2D. Early evidence of retinal neurodegeneration may be used as the first sign of incipient diabetic retinopathy and chronic complications of diabetes mellitus. Longitudinal studies demonstrating long-term effect of GV on neuroretina and possibly intervention studies focusing on reducing $\mathrm{GV}$, or more practically increasing glucose time in range, are warranted.

\section{Relationship between glucose fluctuations and ST-segment resolution in patients with ST-elevation acute myocardial infarction}

Tsuchida $K^{1}$, Nakamura $N^{1}$, Soda $S^{2}$, Sakai $R^{l}$, Nishida $K^{1}$, Hiroki $J^{1}$, Kashiwa $A^{1}$, Fujihara $Y^{1}$, Kimura $S^{1}$, Hosaka $Y^{1}$, TakahashiI $K^{1}$, Oda $H^{1}$

${ }^{I}$ Department of Cardiology, Niigata City General Hospital, Niigata, Japan; ${ }^{2}$ Endocrinology and Metabolism, Niigata City General Hospital, Niigata, Japan

Int Heart J 2017; 58: 328-334

\section{Aims}

To determine whether there is a relationship that exists between glucose variability and electrocardiographic markers of reperfusion injury in patients with ST elevation myocardial infarction (STEMI) undergoing percutaneous coronary intervention (PCI).

\section{Methods}

Sixty-three consecutive patients with STEMI undergoing PCI were prospectively studied by measuring ST segment resolution (STR, \%) using electrocardiograms recorded 60 minutes after PCI. Patients were categorized as STR $\geq 30 \%$ or STR $<30 \%$. All patients in the study had diabetes $(n=30)$, impaired glucose tolerance $(n=26)$, impaired fasting glucose $(n=1)$, or normal glucose tolerance $(n=6)$. Glucose variability was obtained from a CGM system with analysis of MAGE (mg/dL) and area under the curve with reference to mean glucose $\left(\mathrm{AUC}_{\mathrm{MBG}}, \mathrm{mg} / \mathrm{dL} /\right.$ day $)$.

\section{Results}

Both MAGE and $\mathrm{AUC}_{\mathrm{MBG}}$ were significantly higher in STR $<30 \%$. Univariate analysis showed a significant association 
of MAGE $\geq 70 \mathrm{mg} / \mathrm{dL}$ (odds ratio, OR $=17.0$ [95\% CI 1.93, 150.12]; $P<0.001)$ and reperfusion arrhythmias $(\mathrm{OR}=7.6$ [1.32, 44.29]; $P<0.05$ ) as well $\mathrm{AUC}_{\mathrm{MBG}} \geq 20 \mathrm{mg} / \mathrm{dL} /$ day $(\mathrm{OR}=10.9$ [1.92, 61.77]; $P<0.01)$ with delayed STR. Only MAGE $\geq 70 \mathrm{mg} / \mathrm{dL}$ was shown to be predictive of delayed STR $(\mathrm{OR}=22.5$; 95\%CI 2.43, 208.66, $P<0.01)$ in multiple logistic regression analysis.

\section{Conclusions}

Glycemic variability measured by CGM correlated with impaired ST segment resolution in patients with a STEMI undergoing PCI intervention. These results suggest the possibility that intervening to lower glycemic variability may improve myocardial reperfusion injury in patients with a STEMI.

\section{Comments}

There are several studies published to date, including this study by Tsuchida et al., that show glycemic variability correlates with suboptimal reperfusion in patients undergoing PCI, and in patients with unstable angina or a STEMI. Glycemic variability also correlates with poor outcomes in stent intervention in patients undergoing PCI. It is not known at this time whether controlling glycemic variability will have an impact on outcomes of percutaneous coronary intervention. Prospective studies are needed to answer these questions if controlling glycemic variability will improve reperfusion and other factors post coronary intervention.

\section{Post stroke dysglycemia and acute infarct volume growth: a study using continuous glucose monitoring}

Shimoyama $T^{1,2}$, Kimura $K^{1,2}$, Uemura $J^{1}$, Saji $N^{1}$, Shibazaki $K^{1}$

${ }^{I}$ Department of Stroke Medicine, Kawasaki Medical School, Kurashiki, Japan; ${ }^{2}$ Department of Neurological Science, Graduate School of Medicine, Nippon Medical School, Tokyo, Japan

Eur Neurol 2016; 76: 167-174

\section{Aims}

Hyperglycemia (HG) is associated with infarct volume growth after acute ischemic stroke, yet until now, glycemic variability $(\mathrm{GV})$ had not been investigated in acute ischemic stroke patients related to infarct volume growth. In this study, $72 \mathrm{~h} \mathrm{CGM}$ and serial magnetic resonance imaging (MRI) studies were performed to determine whether post-stroke HG and $\mathrm{GV}$ are associated with infarct volume growth.

\section{Methods}

All patients underwent MRI (diffusion-weighted imaging [DWI], magnetic resonance angiography, and $\mathrm{T} 2 *$ gradient echo imaging) and had serum glucose and HbAlc levels measured on admission. HG was defined as serum glucose level $>140 \mathrm{mg} / \mathrm{dL}$. Acute ischemic stroke patients with internal carotid artery (ICA) or middle cerebral artery (MCA) occlusion were recruited, and a CGM device (Medtronic Inc., Northridge, CA) was started within $24 \mathrm{~h}$ of stroke onset. Patients were not included if they did not provide informed consent or if the study was contraindicated due to conditions such as large brain infarcts with herniation and respiratory or cardiac failure. Follow-up MRIs were performed at 24 and $72 \mathrm{~h}$ after admission. Mean glucose level, AUC $>140 \mathrm{mg} / \mathrm{dL}$, and SD of the glucose level were calculated as markers of CGM. Persistent HG was defined as mean glucose level $>140 \mathrm{mg} / \mathrm{dL}$ on CGM. Glucose management (insulin or oral hypoglycemic agents) during CGM was performed when the attending physician judged it necessary.

\section{Results}

A total of 84 patients with ICA or MCA occlusion whose glucose levels were monitored using the CGM device were included. Six were excluded: 5 did not obtain complete CGM data and 1 patient did not undergo follow-up MRI due to illness severity. The data of the remaining 78 patients (35 males; $80.5 \pm 9.6$ years) were used in the analysis. Persistent HG was observed in 26 patients (33.3\%). Diabetes mellitus was more prevalent in the persistent HG group compared with the nonpersistent $\mathrm{HG}$ group (50.0 vs. $9.6 \%$, $P<0.001)$, along with admission glucose level $(170.6 \pm 85.4$ vs. $119.3 \pm 23.8 \mathrm{mg} / \mathrm{dL}, P=0.002)$, and admission $\mathrm{HbA} 1 \mathrm{c}$ $(6.9 \pm 2.8$ vs. $5.6 \pm 0.4 \%, P<0.001)$. The mean CGM glucose level $(180.9 \pm 39.4$ vs. $117.2 \pm 13.8 \mathrm{mg} / \mathrm{dL}, P<0.001)$, AUC $>140 \mathrm{mg} / \mathrm{dL}(44.1 \pm 37.1$ vs. $3.2 \pm 4.4 \mathrm{mg} / \mathrm{dL}, P<0.001)$, and the SD of the glucose level $(34.2 \pm 13.7$ vs. $20.8 \pm 11.5 \mathrm{mg} /$ $\mathrm{dL}, P<0.001)$ were significantly higher in the persistent HG group than in the nonpersistent HG group. Glucose management was performed more often in the persistent $\mathrm{HG}$ group than in the nonpersistent $\mathrm{HG}$ group (26.9 vs. $0.0 \%$, $P<0.001)$. There were no differences in stroke etiology or baseline infarct volume (ischemic core) (52.4 \pm 44.6 vs. $61.6 \pm 71.1 \mathrm{~mL}, P=0.928$ ) between the two groups, without any difference in the rate of thrombolysis or recanalization rates $(46.2$ vs. $51.9 \%, P=0.810)$. Infarct volume growth at $24 \mathrm{~h}$ was larger in the persistent $\mathrm{HG}$ group than in the nonpersistent $\mathrm{HG}$ group $(58.9 \pm 80.5$ vs. $21.2 \pm 38.5 \mathrm{~mL}$, $P=0.003$ ). Infarct volume growth at $72 \mathrm{~h}$ was nonsignificantly larger in the persistent $\mathrm{HG}$ group than in the nonpersistent HG group $(78.7 \pm 113.2$ vs. $45.6 \pm 53.7 \mathrm{~mL}$, $P=0.081)$. The change of DWI infarct volume $\geq 30 \%$ were more observed in the persistent HG group than in the nonpersistent HG group (76.9 vs. $50.0 \%, P=0.029$ for $24 \mathrm{~h} ; 88.5$ vs. $65.4 \%, P=0.034$ for $72 \mathrm{~h})$. Both the mean CGM glucose level ( $r=0.433, P<0.001$ for $24 \mathrm{~h} ; r=0.308, P=0.006$ for $72 \mathrm{~h})$, and AUC $>140 \mathrm{mg} / \mathrm{dL}(r=0.417, P<0.001$ for $24 \mathrm{~h}$; $r=0.277, P=0.014$ for $72 \mathrm{~h}$ ) were significantly correlated with acute infarct volume growth, while SD of the CGM glucose level was associated with infarct volume growth at $24 \mathrm{~h}(r=0.303, P=0.007)$, but not significantly at $72 \mathrm{~h}$ $(r=0.195, P=0.088)$.

\section{Conclusion}

Post-stroke HG is associated with acute infarct volume growth in patients with arterial occlusion, with a possible role of glycemic variability on the early development of cerebral ischemia. 


\section{Comments}

The first results on GV and early acute infarct volume stroke, as reported in this study, are inconclusive because they cannot be clearly separated from the effect of persistently high blood glucose. At the same time, they are well in line with observations in other organ systems, where GV consistently increases the injury. Reading the data, one gets an impression that the routine treatment of hyperglycemia in this critically ill population is quite relaxed, and considerable hyperglycemia seems to be tolerated. Therefore, patients who have suffered an acute cerebral stroke are another crucial population in which intervention studies addressing persistent hyperglycemia as well as $\mathrm{GV}$ are paramount.

\section{Impact of glycemic variability on chromatin remodeling, oxidative stress and endothelial dysfunction in type 2 diabetic patients with target $\mathrm{HbA}_{\mathbf{1 c}}$ levels}

Costantino $S^{1,2}$, Paneni $F^{1,2}$, Battista $R^{3}$, Castello $L^{4}$, Capretti $G^{4}$, Chiandotto $S^{4}$, Tanese $L^{5}$, Russo $G^{6}$, Pitocco $D^{5}$, Lanza $G A^{6}$, Volpe $M^{4,7}$, Lüscher $T F^{2}$, Cosentino $F^{1}$

${ }^{1}$ Cardiology Unit, Department of Medicine Solna, Karolinska University Hospital, Stockholm, Sweden; ${ }^{2}$ Center for Molecular Cardiology, University of Zürich, and University Heart Center, Department of Cardiology, University Hospital Zurich, Switzerland; ${ }^{3}$ Internal Medicine Unit, Civil Hospital, Sora, Italy; ${ }^{4}$ Cardiology, Department of Clinical and Molecular Medicine, University of Rome Sapienza, Italy; ${ }^{5}$ Diabetes Care Unit, Internal Medicine, Catholic University, Rome, Italy; ${ }^{6}$ Department of Cardiovascular Sciences, Catholic University, Rome, Italy; ${ }^{7}$ Istituto Di Ricovero e Cura a Carattere Scientifico Pozzilli (IS), Italy

Diabetes 2017; 66: 2472-2482

\section{Aims}

Attempts to slow/prevent cardiovascular disease (CVD) progression in T2D with intensive glycemic control have been disappointing for a long time. Epigenetic modifications are important in the pathogenesis of CVD, as they significantly affect the expression of oxidant and inflammatory genes. Transient hyperglycemia triggers inflammation through chromatin changes that persist even after restoration of normoglycemia. The present study investigated whether glycemic variability causes persistent epigenetic remodeling of adaptor protein $\mathrm{p} 66^{\mathrm{Shc}}$, a key experimental driver of mitochondrial oxidative stress, in people with T2D.

\section{Methods}

Thirty-nine consecutive patients with uncontrolled T2D (HbA1c $>7.5 \%$ ), without overt atherosclerotic vascular disease or an estimated glomerular filtration rate of $<60 \mathrm{~mL} /$ $\min$ per $1.73 \mathrm{~m}^{2}$ were recruited. Twenty-four healthy subjects of similar age and sex, with normal blood pleasure, LDL cholesterol, and fasting plasma glucose, not taking any medications, were recruited during the same period. Baseline evaluation in both study groups included evaluation of epi- genetic changes of the $\mathrm{p} 66^{\mathrm{Shc}}$ promoter in isolated peripheral blood monocytes (DNA methylation and histone 3 acetylation), 24-h urinary excretion rates of 8 -isoprostaglandinF $2 \alpha$ (8-isoPGF $2 \alpha$ ), and brachial artery flow-mediated dilation (FMD). Patients with poorly controlled T2D started a comprehensive, intensive treatment program, were prospectively followed for 6 months, and then repeated the same tests with an addition of CGM to assess mean amplitude of glycemic excursions (MAGE) and postprandial incremental area under the curve of blood glucose levels (AUCpp).

\section{Results}

Median $\mathrm{HbAlc}$ decreased from $7.8 \%$ (range 7.5-8.5\%) to $6.6 \%$ (range $6.3-7.0 \%$ ) $P<0.001$. No hypoglycemic events requiring intervention were recorded. Anthropometric parameters (body weight/BMI) and other cardiovascular risk factors (blood pressure, lipids) did not change throughout the study. Flow-mediated dilation (FMD) of the brachial artery was significantly impaired in T2D patients as compared with controls $(4.9[95 \%$ CI 3.7, 5.8] vs. $8.5[7.3,9.8] \%, P<0.001)$ (values are median with 95\% CI). Endothelium-independent dilatation to nitroglycerine was similar in the two groups $(11.85[10.9,13.6]$ vs. $11.80[8.5,14.8] \%, P=0.69)$. Urinary excretion rates of 8-isoPGF2 $\alpha$ was higher in participants with T2D (360.9 [351.2, 411.5] vs. 155.8 [95.2, 206.3] pg/mg of creatinine, $P<0.001)$. FMD and 8 -isoPGF2 $\alpha$ did not improve after 6 months of intensive diabetes management compared with baseline values $(4.8[4.1,6.2] \%, P=0.16$, and 357.5 [342.9, 373.7] $\mathrm{pg} / \mathrm{mg}$ of creatinine, $P=0.10$, respectively). p66 ${ }^{\text {Shc }}$ gene expression was significantly higher in peripheral blood monocytes (PBM) isolated from participant with T2D compared with controls $(4.87 \pm 2.91$ vs. $1.00 \pm 0.55 \mathrm{AU}$, $P<0.001)\left(\right.$ mean \pm SD). p66 ${ }^{\text {Shc }}$ mRNA levels were independently associated with 8 -isoPGF $2 \alpha$ urinary excretion and FMD in linear regression models, regardless of potential confounders. Upregulation of $\mathrm{p} 66^{\text {Shc }}$ was not reverted by intensive diabetes management $(4.77 \pm 2.88 \mathrm{AU}, P=0.39$, vs. baseline). DNA methylation was significantly reduced in PBM isolated from participants with T2D compared with controls $(43.5 \pm 19.3$ vs. $100 \pm 0.37 \%, P<0.001)$, and this was not improved after intensive diabetes management $(49.2 \pm 22.7 \%$, $P=0.53$, vs. baseline) (mean \pm SD). Only subjects with MAGE and AUCpp above the 50th percentile had adverse epigenetic remodeling of $\mathrm{p}^{\mathrm{Shc}}{ }^{\mathrm{Shc}}$ promoter. Linear regression models adjusted for age, gender, BMI, and glucose lowering treatment confirmed that MAGE and AUCpp were independently associated with adverse epigenetic remodeling of $\mathrm{p} 66^{\mathrm{Shc}}$.

\section{Conclusion}

Glucose variability was associated with chromatin remodeling and may explain the persistent vascular dysfunction in people with T2D within target HbAlc levels.

\section{Comments}

Very few studies addressed the effect of GV on chromatin level, and the results discussed above are unique, as they demonstrate a discrepancy between $\mathrm{HbAlc}$ and $\mathrm{GV}$ in their long-term effect on chromatin remodeling. It is fair to assume that more studies on the subcellular 
level related to $\mathrm{GV}$ will follow, as they may discover potential targets for novel therapies. After many clinical observational studies and some basic research, prospective randomized trials targeting $\mathrm{GV}$ and studying the effect of more time in range on clinical and basic parameters will possibly shed new light on our understanding of mechanisms leading to chronic diabetes complications and their prevention.

\section{Conclusion}

Looking on the very long list of publications related to CGM/FGM published in the last 12 months - both from randomized controlled trials and prospective routine-use followup studies-along with several long-term observations from centers-of-excellence $(19,20)$, and finally, official guidelines, one can now conclude that CGM/FGM is a mainstream routine treatment modality with well-proven safety and efficiency. Also, the penetration of CGM/FGM into routine use is improving, admittedly at a slower rate than some have predicted or expected. We can imagine that the major increase in this routine use will come with its nonadjunctive use without SMBG confirmation (21). Replacement of SMBG, along with modifiable psychosocial variables, will also positively influence long-term adherence to CGM/FGM (22). Finally, it will be the quality of life (23) and the increased feeling of safety $(24,25)$ that will likely position CGM-alone or in combination with a version of artificial pancreas-as the predominant way of self-monitoring glucose. Additionally, HCPs will acquire more user friendly and unified data interpretation algorithms (26), likely incorporated into widespread platforms. This will be accompanied by increasingly available reimbursement, both from large public and private insurance systems (27).

We did not include technical innovations in our 2017 update, as most of these important devices and systems are still in the middle of clinical studies. Very exciting novel technologies may soon additionally swing the use of CGM even closer to more people with diabetes.

\section{Author Disclosure Statement}

T.B. served on advisory boards of Novo Nordisk, Sanofi, Eli Lilly, Boehringer, Medtronic, and Bayer Health Care. T.B.'s institute received research grant support from Abbott, Medtronic, Novo Nordisk, GluSense, Sanofi, and Sandoz, and T.B. received honoraria for participating on the speaker's bureaus of Eli Lilly, Bayer, Novo Nordisk, Medtronic, Sanofi, and Roche. T.B. owns stocks of DreamMed.

B.W.B. receives consultancy and speaker fees from Adocia, Astra Zeneca, Bayer, Intarcia, Janssen, Mannkind, Medtronic, Novo Nordisk, and Sanofi. B.W.B.'s employer, Atlanta Diabetes Associates, has received research and grant support from Abbott, Becton Dickinson, Boehringer Ingleheim, Diasome, DexCom, Janssen, Lilly, Mannkind, Medtronic, Novo Nordisk, Sanofi, and Senseonics.

\section{References}

1. Peters AL, Ahmann AJ, Battelino T, Evert A, Hirsch IB, Murad MH, Winter WE, Wolpert H. Diabetes technology- continuous subcutaneous insulin infusion therapy and continuous glucose monitoring in adults: An Endocrine Society Clinical Practice Guideline. J Clin Endocrinol Metab 2016; 101: 3922-3937.

2. Benkhadra K, Alahdab F, Tamhane S, Wang Z, Prokop LJ, Hirsch IB, Raccah D, Riveline JP, Kordonouri O, Murad MH. Real-time continuous glucose monitoring in type 1 diabetes: a systematic review and individual patient data meta-analysis. Clin Endocrinol (Oxf) 2017; 86: 354-360.

3. McGill JB, Ahmann A. Continuous glucose monitoring with multiple daily insulin treatment: outcome studies. Diabetes Technol Ther 2017; 19: S3-S12.

4. Slattery D, Choudhary P. Clinical use of continuous glucose monitoring in adults with type 1 diabetes. Diabetes Technol Ther 2017; 19: S55-S61.

5. Carlson AL, Mullen DM, Bergenstal RM. Clinical use of continuous glucose monitoring in adults with type 2 diabetes. Diabetes Technol Ther 2017; 19: S4-S11.

6. Lal RA, Maahs DM. Clinical use of continuous glucose monitoring in pediatrics. Diabetes Technol Ther 2017; 19: S37-S43.

7. Wright EE Jr, Gavin JR 3rd. Clinical use of professional continuous glucose monitoring. Diabetes Technol Ther 2017; 19: S12-S15.

8. Rodbard D. Continuous glucose monitoring: a review of recent studies demonstrating improved glycemic outcomes. Diabetes Technol Ther 2017; 19: S25-S37.

9. Schnell O, Barnard K, Bergenstal R, Bosi E, Garg S, Guerci B, Haak T, Hirsch IB, Ji L, Joshi SR, Kamp M, Laffel L, Mathieu C, Polonsky WH, Snoek F, Home P. Role of continuous glucose monitoring in clinical trials: recommendations on reporting. Diabetes Technol Ther 2017; 19: 391-399.

10. Dovč K, Bratina N, Battelino T. A new horizon for glucose monitoring. Horm Res Paediatr 2015; 83: 149-156.

11. Sekido K, Sekido T, Kaneko A, Hosokawa M, Sato A, Sato Y, Yamazaki M, Komatsu M. Careful readings for a flash glucose monitoring system in nondiabetic Japanese subjects: individual differences and discrepancy in glucose concentration after glucose loading [Rapid Communication]. Endocr J 2017; 64: 827-832.

12. Scaramuzza AE, Arnaldi C, Cherubini V, Piccinno E, Rabbone I, Toni S, Tumini S, Candela G, Cipriano P, Ferrito L, Lenzi L, Tinti D, Cohen O, Lombardo F. Recommendations for the use of sensor-augmented pumps with predictive low-glucose suspend features in children: the importance of education. Pediatr Diabetes 2017; 18: 882-889.

13. Petruzelkova L, Pickova K, Sumnik Z, Soupal J, Obermannova B. Effectiveness of SmartGuard technology in the prevention of nocturnal hypoglycemia after prolonged physical activity. Diabetes Technol Ther 2017; 19: 299304.

14. Scaramuzza AE, Arnaldi C, Cherubini V, Piccinno E, Rabbone I, Toni S, Tumini S, Candela G, Cipriano P, Ferrito L, Lenzi L, Tinti D, Cohen O, Lombardo F. Use of the predictive low glucose management (PLGM) algorithm in Italian adolescents with type 1 diabetes: CareLink ${ }^{\mathrm{TM}}$ data download in a real-world setting. Acta Diabetol 2017; 54: 317-319.

15. Pate T, Klemenčič S, Battelino T, Bratina N. Fear of hypoglycemia, anxiety, and subjective well-being in parents of children and adolescents with type 1 diabetes. J Health 
Psychol 2016 Jun 7; pii: 1359105316650931. DOI 10.1177/1359105316650931 [Epub ahead of print].

16. Bratina N, Shalitin S, Phillip M, Battelino T. Type 1 Diabetes in the young: organization of two national centers in Israel and Slovenia. Zdr Varst 2015; 54: 139-145.

17. Stem MS, Dunbar GE, Jackson GR, Farsiu S, Pop-Busui R, Gardner TW. Glucose variability and inner retinal sensory neuropathy in persons with type 1 diabetes mellitus. Eye (Lond) 2016; 30: 825-832.

18. Kwai NC, Arnold R, Poynten AM, Krishnan AV. Association between glycemic variability and peripheral nerve dysfunction in type 1 diabetes. Muscle Nerve 2016; 54: 967-969.

19. Gómez AM, Marín Carrillo LF, Arévalo Correa CM, Muñoz Velandia OM, Rondón Sepúlveda MA, Silva Herrera JL, Henao Carrillo DC. Maternal-Fetal Outcomes in 34 pregnant women with type 1 diabetes in sensoraugmented insulin pump therapy. Diabetes Technol Ther 2017; 19: 417-422.

20. Gómez AM, Marín Carrillo LF, Muñoz Velandia OM, Rondón Sepúlveda MA, Arévalo Correa CM, Mora Garzón E, Cuervo Diaz MC, Henao Carrillo DC. Long-term efficacy and safety of sensor augmented insulin pump therapy with low-glucose suspend feature in patients with type 1 diabetes. Diabetes Technol Ther 2017; 19: 109-114.

21. Forlenza GP, Argento NB, Laffel LM. Practical considerations on the use of continuous glucose monitoring in pediatrics and older adults and nonadjunctive use. Diabetes Technol Ther 2017; 19: S13-S20.

22. Giani E, Snelgrove R, Volkening LK, Laffel LM. Continuous glucose monitoring (CGM) adherence in youth with type 1 diabetes: associations with biomedical and psychosocial variables. J Diabetes Sci Technol 2017; 11: 476-483.

23. Polonsky WH, Hessler D, Ruedy KJ, Beck RW; DIAMOND Study Group. The impact of continuous glucose monitoring on markers of quality of life in adults with type 1 diabetes: further findings from the DIAMOND randomized clinical trial. Diabetes Care 2017; 40: 736-741.

24. Klemenčič S, de Wit M, Rutar M, Battelino T, Bratina N. Annual psychological screening in youth and young adults with type 1 diabetes. Zdr Varst 2015; 54: 103-111.

25. Litchman ML, Allen NA. Real-time continuous glucose monitoring facilitates feelings of safety in older adults with type 1 diabetes: a qualitative study. J Diabetes Sci Technol 2017; 11: 988-995.

26. Hirsch IB, Balo AK, Sayer K, Garcia A, Buckingham BA, Peyser TA. A simple composite metric for the assessment of glycemic status from continuous glucose monitoring data: implications for clinical practice and the artificial pancreas. Diabetes Technol Ther 2017; 19: S38-S48

27. Graham C. Continuous glucose monitoring and global reimbursement: an update. Diabetes Technol Ther 2017; 19: S60-S66. 